\title{
Degenerative mitral valve disease with emphasis on mitral valve prolapse
}

\author{
D Pellerin, S Brecker, C Veyrat
}

Heart 2002;88(Suppl IV):iv20-iv28

D egenerative mitral valve disease is responsible for the syndromes of billowing mitral leaflet, mitral valve prolapse (MVP), floppy mitral valve, and flail leaflet. ${ }^{1-6}$ The pathology of these is mainly caused by myxomatous infiltration and fibroelastic deficiency.

In the 1960s, Reid ${ }^{7}$ and Barlow and colleagues ${ }^{1}$ proposed that mid to late systolic clicks and apical late systolic murmurs were of mitral valvar origin. This origin was further documented by intracardiac phonocardiography. ${ }^{8}$ Criley and colleagues used "mitral valve prolapse" to describe posterior mitral leaflet motion in systole." Since then, MVP has remained a diagnosis of sustained interest and controversy.

Because MVP is asymptomatic or has a non-specific clinical presentation, the disease is often detected by the non-ejection systolic click of the mitral valve and the late systolic murmur. MVP is clinically benign with potential for serious complications in otherwise healthy people, such as degenerative mitral regurgitation and infective endocarditis. Age and sex distributions as well as the frequencies of chest pain, dyspnoea, and ECG abnormalities were not significantly different between subjects with and without MVP, ${ }^{10-12}$ demonstrating that the previously reported associations were probably caused by a selection bias. These recent studies also showed that patients with MVP had lower body mass index than those without MVP. Many disorders have been associated with MVP but we do not know whether these associations are a casual coincidence, a common link or an expression of a genetic disturbance.

\section{HISTOLOGY}

Histologic patterns of degenerative mitral valve disease include myxomatous infiltration, fibroelastic deficiency, collagen alterations, and mucopolysaccharide accumulation. ${ }^{13}$ Elongated or ruptured chordae are often associated with these abnormalities. Because the distribution of mitral leaflet layers, namely auricularis, spongiosa, fibrosa, and ventricularis, is different in the basal, middle, and distal thirds of the leaflet, histologic abnormalities may vary accordingly. Myxomatous infiltration is characterised by thickening and proliferation of the spongiosa with pooling of glycosaminoglycans. Spongiosa invades fibrosa giving the appearance of cystic spaces and less dense collagen. Collagen alterations are characterised by fragmentation of collagenous bundles within the fibrosa. Elastic fibre alterations are characterised by disrupted, fragmented, and granular elastic fibres that form an amorphous clump. The number of elastic fibres is increased in the abnormal area. In the billowing mitral leaflet syndrome (Barlow's disease), the valve has excess tissue and a myxoid appearance. The annulus is dilated, and the chordae tendinae may be thin or thickened. In contrast, the fibroelastic deficiency is usually found in elderly patients. There is tissue thickening of the prolapsed area but the remaining valve tissue and chordae are thinner and more transparent than normal. There is no excess tissue. The annulus is moderately dilated. The term pellucid mitral valve has also been used to refer to this entity. ${ }^{4}{ }^{13}$

\section{GENETICS}

MVP has been reported to be an autosomal dominant trait with incomplete penetrance and with age and sex dependent expression. ${ }^{14}$ However, these reports were based on nonspecific diagnostic criteria and on hospital based defined probands, which introduced a selection bias in favour of more severe disease. Mapping studies have linked MVP to chromosome $\mathrm{Xq}_{2} 8^{15}$ and 16p11.2-p12.1. ${ }^{14}$ Future research will determine the genetic and environmental contributions to the phenotypic expression of MVP.

\section{FACTORS INFLUENCING SEVERITY}

Several factors may influence MVP severity. MVP is linked to the variable relation between left ventricular (LV) size and mitral annulus size ${ }^{16}$ and occurs as LV size is decreased or LV shape is altered. ${ }^{17}$ Accordingly, postural auscultatory changes with a striking increase in the upright position were related to variations in left ventricular dimensions. ${ }^{18}$ A decreased LV volume and size may be responsible for the high incidence of MVP in anorexia nervosa; weight gain was shown to eliminate MVP. $^{19}$

\section{PREVALENCE}

Early findings of $5-15 \%$ prevalence have been overestimated because of the use of non-uniform and non-specific echo criteria. Diagnostic techniques have included auscultation, phonocardiography, M mode and two dimensional echo, LV angiography, and direct histological inspection of the mitral valve. However, the positive predictive value of a physician's diagnosis of MVP was only $7 \%$ in men and $4 \%$ in women. ${ }^{12}$ The application of non-specific $\mathrm{M}$ mode echo criteria was responsible for the highest prevalence of a diagnosis of MVP among healthy young people. Description of the three dimensional saddle shape of the mitral annulus explained the appearance of MVP isolated in apical four chamber view $\mathrm{w}^{20-22}$ and resulted in the use of more specific diagnostic criteria obtained from the two dimensional parasternal long axis view. Recent observational studies demonstrated that MVP has a prevalence of $1.6-2.4 \%$ in adults. ${ }^{12} 23$

\section{DIAGNOSIS}

Rigorous echo criteria for the diagnosis of MVP were used in an unselected, community based sample of patients. ${ }^{23}$ Classic MVP was defined as superior displacement of the mitral leaflets of more than $2 \mathrm{~mm}$ during systole and as maximal leaflet thickness of at least $5 \mathrm{~mm}$ during diastasis. Non-classic prolapse was defined as displacement of more than $2 \mathrm{~mm}$ with maximal leaflet thickness of less than $5 \mathrm{~mm}$. Using these criteria in 3491 subjects, $2.4 \%$ had MVP with $1.3 \%$ of classic prolapse and $1.1 \%$ of non-classic prolapse.

MVP is now understood not as a single entity but as a spectrum of abnormalities ${ }^{24}$ in patients with midsystolic click with or without a mitral regurgitant murmur. Patients with mild billowing and morphologically normal appearing leaflets are normal variants because their risk of complications is probably

Abbreviations: LV, left ventricular; MVP, mitral valve prolapse; NYHA, New York Heart Association; TOE, transoesophageal echocardiography; TTE, transthoracic echocardiography 
not different from that in the general population. ${ }^{25}$ This more benign pattern of disease in the community has also been recognised in patients with Wolf-Parkinson-White syndrome ${ }^{26}$ and hypertrophic cardiomyopathy. ${ }^{27}$ In contrast, patients with redundant and thickened leaflets caused by pronounced myxomatous infiltration and elongated chordae have a primary form of the disease associated with an increased risk of complications or associated with an increased risk for sudden death. ${ }^{28-31}$ The primary form of MVP often occurs in patients with connective tissue syndromes or in older men. ${ }^{28}$ Exercise induced mitral regurgitation may be a predictor of morbid events in subjects with MVP and no mitral regurgitation at rest. ${ }^{32}$

\section{MVP RELATED COMPLICATIONS}

Severe mitral regurgitation was present in only $2 \%$ of subjects included into the Strong heart study ${ }^{11}$ and occurred in $7 \%$ of the subjects with classic prolapse, as compared with none of the subjects who had non-classic prolapse and $0.5 \%$ of those without prolapse. ${ }^{23}$ MVP was present in $26.9 \%$ of subjects with moderate or severe mitral regurgitation in the Framingham heart study. ${ }^{10}$ The complications of MVP occur disproportionately in older patients and men. ${ }^{29}$ Although the risk of progressive mitral regurgitation seems to be greater in patients with both murmur and click than in those with isolated click, the natural history of MVP in the community remains incompletely studied. Hospital referral studies have been crucial in highlighting potential complications of MVP including severe mitral regurgitation, infective endocarditis, heart failure, and sudden death.

Degenerative mitral regurgitation is one of the most frequent cardiovascular disorders requiring surgery. ${ }^{43}$ MVP is the most common cause of mitral regurgitation when assessed on the basis of surgical findings and histologic examinations of the excised valves at the time of surgery. Chordal rupture was found to be the most frequent cause of acute mitral regurgitation and related heart failure in patients with unknown mitral valve disease, and the most frequent cause of unexpected rapid aggravation in patients with known mitral regurgitation.

\section{NOMENCLATURE AND CLASSIFICATION}

It is crucial that the members of a team-namely, cardiologist, surgeon, anaesthetist and pathologist-use the same nomenclature and classification of disease.

Carpentier and colleagues classified mitral valve incompetence into three types. ${ }^{3}$ In type II, the free edge of one or both leaflets overrides the plane of the annulus during systole. Type II lesions are related to excess leaflet tissue, elongated or ruptured chordae, dysfunction or ruptured papillary muscle. Types I and III may be associated with type II. In type I, the free edges of the leaflets remain below the plane of the annulus during systole and open normally during diastole. Mitral regurgitation is related to annular dilation or leaflet perforation. In type III, one or both leaflets do not open fully during diastole. Mitral regurgitation is related to restriction of leaflet motion of rheumatic or ischaemic origin.

Carpentier and colleagues in France and Duran and associates in Spain have both proposed nomenclatures of the mitral valve. $^{34}{ }^{35}$ The two nomenclatures are shown in fig 1 . The Carpentier nomenclature will be used in this review. The valve is divided into two leaflets, posterior and anterior. The posterior leaflet is further divided into three scallops, P1, P2, and P3, which are anatomically evident. $\mathrm{Pl}$ is adjacent to the anterolateral commissure, close to the left atrial appendage. $\mathrm{P} 3$ is adjacent to the posteromedial commissure. The anterior leaflet is also divided into three scallops, $\mathrm{Al}, \mathrm{A} 2$, and $\mathrm{A} 3$ facing the corresponding scallops of the posterior leaflet. $\mathrm{P} 2$ prolapse is the most frequent abnormality.
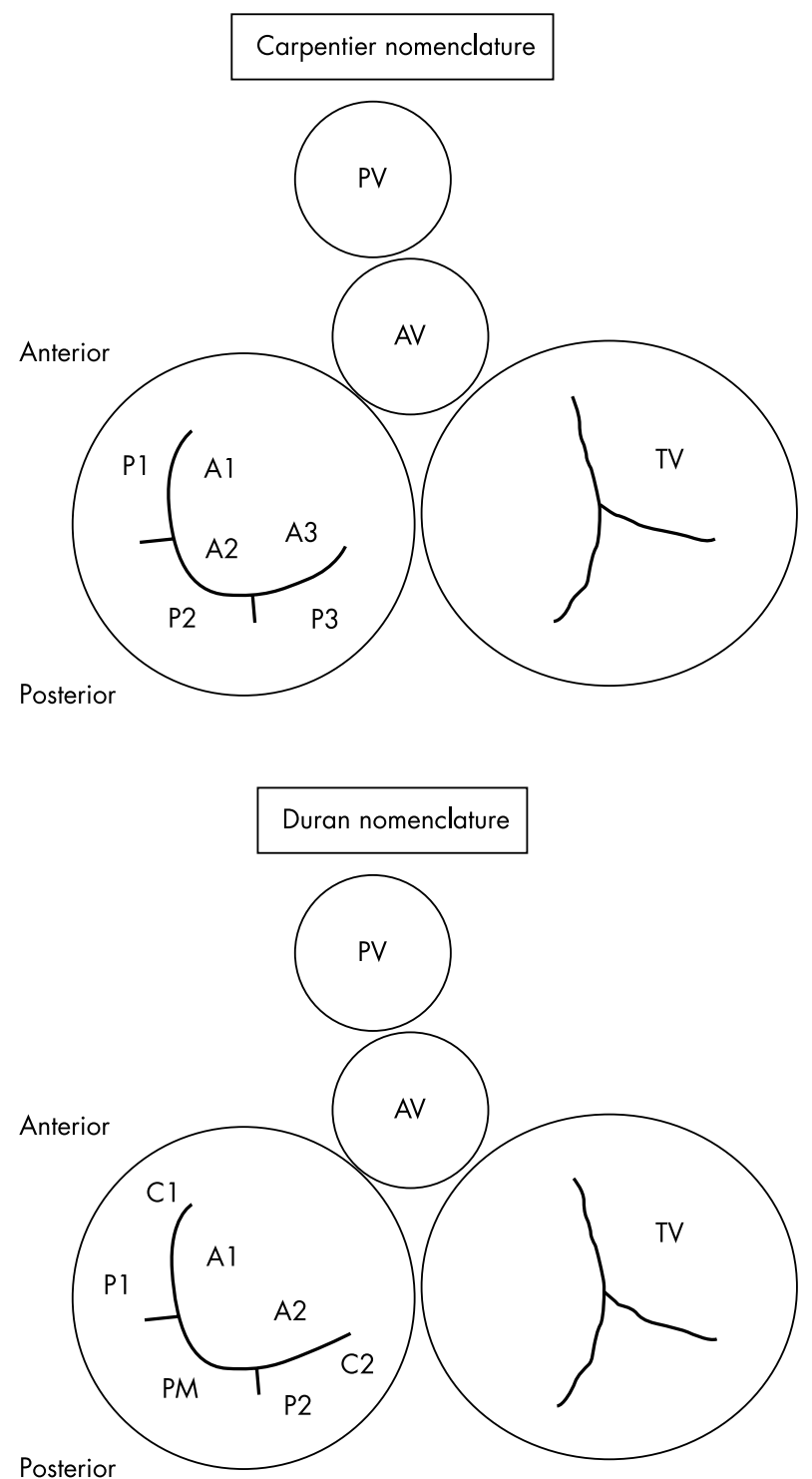

Posterior

Figure 1 Carpentier and Duran nomenclatures of the mitral valve. In the Duran nomenclature, the three scallops of the posterior leaflet are named P1, PM (middle), and P2. The anterior leaflet has only two scallops A1 and A2. The Carpentier nomenclature is described in the text. AV, aortic valve; PV, pulmonic valve; TV, tricuspid valve.

In the billowing mitral leaflet syndrome (Barlow's disease), there is bulging of one or both leaflets into the left atrium cavity caused by excess mitral leaflet tissue and elongated chordae tendinae. The scallop free edge is on the ventricular side, ahead of the line of the annulus during systole. Even when the non-ejection click is present, the mitral valve is often competent. In the MVP syndrome, there is a loss of normal systolic apposition of the leaflet edges. A prolapse mitral scallop protrudes into the left atrium during systole and the scallop free edge is beyond the annular plane. A flail mitral leaflet entirely protrudes into the left atrium due to ruptured chordae. A flail leaflet is identified as upturning of the leaflet tip towards the atrium as opposed to the downturning towards the left ventricle seen in prolapse. A completely flail leaflet is accompanied by severe mitral regurgitation. Floppy mitral valve describes extreme billowing, mitral valve prolapse, and mitral regurgitation.

\section{ECHO ASSESSMENT}

The aims of the echo assessment are to quantify mitral regurgitation, evaluate the effect on ventricular size and function, to 


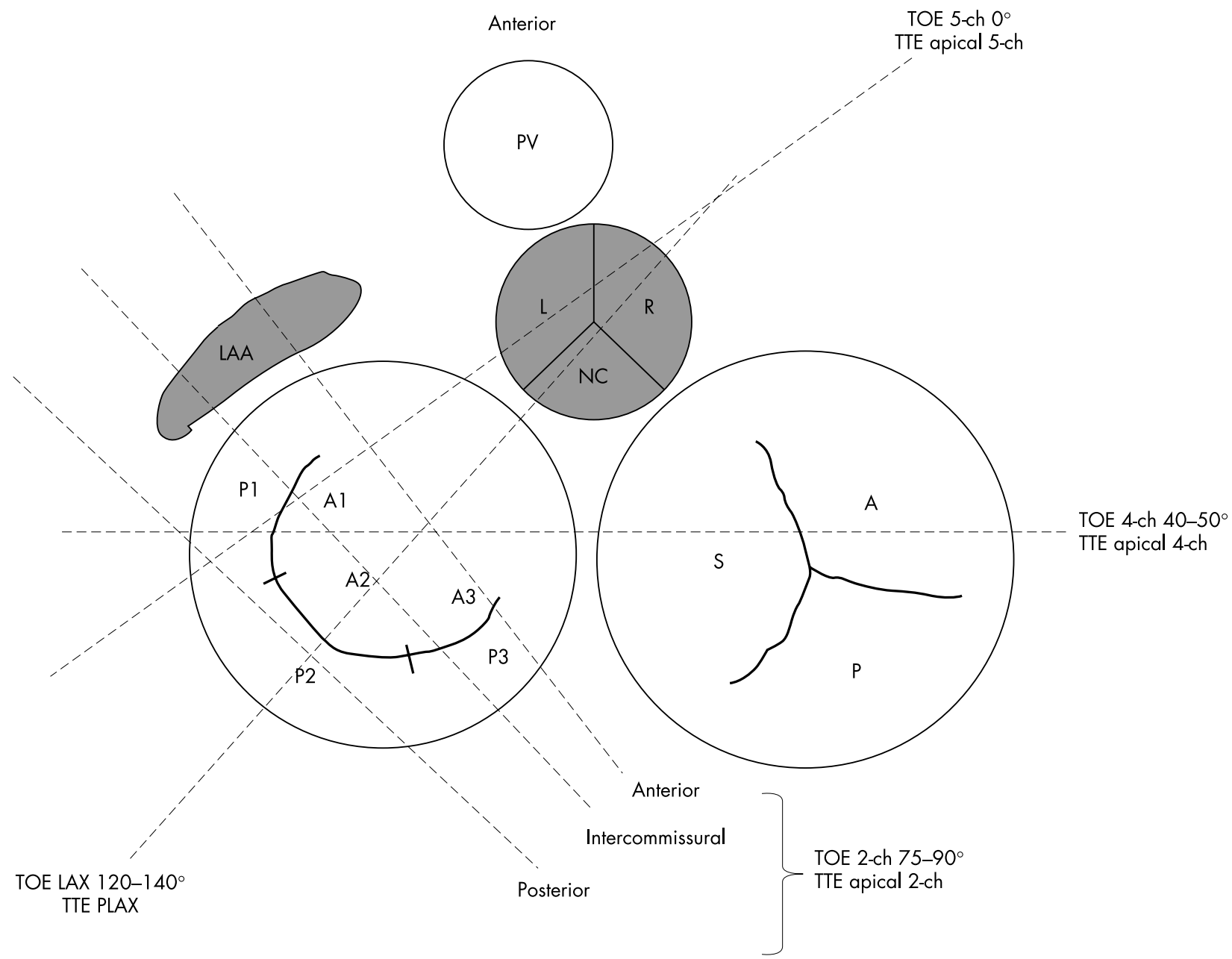

Figure 2 Cross sectional drawing of the heart at the level of the atrioventricular valves. Dotted lines show the planes of the different views obtained during TOE or TTE studies. Left atrial appendage and aortic valve are the landmarks that must be seen or not on the image according to the view. For example, the four chamber view excludes the left ventricular outflow tract and the aortic valve. Figure 2 and table 1 are closely related. AV, aortic valve; LAA, left atrial appendage; LAX, long axis view; PLAX, parasternal long axis view; PV, pulmonic valve, TOE, transoesophageal echo; TTE, transthoracic echo.

describe location and extension of pathology including detection of commissural jets, annular calcifications, subvalvar apparatus abnormalities, and possible associated lesions. The mechanism of the regurgitation must be determined. These objectives can be achieved by transthoracic echocardiography (TTE) in many cases. A multiplane transoesophageal echocardiography (TOE) study is necessary when TTE image quality is poor or when severe mitral regurgitation requires surgery, in order to select patients who will benefit from mitral valve repair. Information given by TTE determines the timing of the TOE assessment that could be performed before the decision of surgery or in the operating theatre before surgery.

Figure 2 shows the planes of the different views of the atrioventricular valves obtained during TOE or TTE studies.

Quantitative assessment of mitral regurgitation usually begins with two dimensional and colour Doppler flow mapping to detect moderate to severe regurgitation. ${ }^{36}$ However, extension of colour regurgitant jet into the left atrium cannot be used as a criterion of severe mitral regurgitation caused by severe underestimation of regurgitant volume with adherent or eccentric jets. Severity of regurgitation mainly depends on anatomy and extension of lesions seen on grey scale images. In addition, several criteria for severe mitral regurgitation have been described based on semiquantitative methods including peak $\mathrm{E}$ velocity on transmitral flow $>1.5 \mathrm{~m} / \mathrm{s}$, ratio of mitral to aortic time velocity integral $>1.3$ (in the absence of aortic regurgitation, mitral stenosis, prosthetic mitral valve or atrial fibrillation), regurgitant jet width at its origin or vena contracta width $>5.5 \mathrm{~mm}$ on TOE $120-140^{\circ}$ view or $>5 \mathrm{~mm}$ on TTE apical views, and reverse $S$ wave on two pulmonary venous flow recordings. Criteria for a regurgitation of grade $\geqslant 3$ have recently been described using the proximal isovelocity surface area method including regurgitant flow rate $>110 \mathrm{ml} / \mathrm{s}$, effective regurgitant orifice area $>0.4 \mathrm{~cm}^{2}$, regurgitant volume $>50 \mathrm{ml}$, and regurgitant fraction $>50 \%$. However, this method is less accurate when the regurgitant jet is eccentric. Although centrally directed jets may occur when both leaflets are affected, MVP typically causes eccentric regurgitation.

Assessment of mitral regurgitation repercussion includes measurements of LV end diastolic diameter, LV end systolic diameter, LV ejection fraction, left atrial size, ratio of right ventricular diameter to LV diameter at basal level in apical four chamber view, assessment of LV filling pressure, cardiac output, and systolic pulmonary artery pressure.

A scallop-by-scallop evaluation of leaflet structure and mobility is mandatory to assess location and extension of pathology and to select patients for mitral valve repair. Table 1 shows the corresponding views of the mitral valve obtained by TTE and TOE with observed scallops. A systematic approach should always be performed, ${ }^{37}$ including the four major views of the mitral valve (figs 3-8) indicated in the table. The three 


\begin{tabular}{|c|c|c|}
\hline Transthoracic echocardiography & Transoesophageal echocardiography & Scallops \\
\hline Apical 5 chamber & 5 chamber, $0^{\circ}$ & $\begin{array}{l}\text { A1-P2, upper oesophagus } \\
\text { A2-P2 }\end{array}$ \\
\hline- & $\begin{array}{l}4 \text { chamber, } 0^{\circ} \\
\text { exclude } A V \text { and LVOT }\end{array}$ & A2-P2/A3-P3 \\
\hline${ }^{*}$ Apical 4 chamber & $\begin{array}{l}\text { * } 4 \text { chamber, } 40-50^{\circ} \\
\text { mid oesophagus } \\
\text { exclude } A V \text { and LVOT }\end{array}$ & A3-A2-P1 \\
\hline- & $\begin{array}{l}2 \text { chamber anterior, } 75-90^{\circ} \\
\text { one coaptation point, LAA visible }\end{array}$ & P3-A3-A2 \\
\hline${ }^{*}$ Apical 2 chamber & $\begin{array}{l}\text { *Intercommissural } 2 \text { chamber, } 75-90^{\circ} \\
\text { two coaptation points, LAA visible }\end{array}$ & P3-A2-P1 \\
\hline- & $\begin{array}{l}2 \text { chamber posterior, } 75-90^{\circ} \\
\text { no coaptation point }\end{array}$ & (P3)-P2-(P1) \\
\hline- & 2 chamber, $100-110^{\circ}$ & $\mathrm{P} 2-\mathrm{A} 2-\mathrm{A} 1$ \\
\hline *Parasternal LAX & ${ }^{*} \operatorname{LAX}, 120-140^{\circ}$ & P2-A2 \\
\hline *Parasternal SAX & ${ }^{*}$ Gastro-oesophageal junction $0^{\circ}$ & All \\
\hline - & Transgastric, $90^{\circ}$ & P3-A2-P1 \\
\hline
\end{tabular}

different TOE two chamber views are obtained by a clockwise rotation of the shaft of the probe. The two chamber anterior view shows a short segment of the posterior leaflet $\mathrm{P} 3$ and a long anterior segment A3-A2. The left atrial appendage must be seen. In the intercommissural two chamber view, there are two coaptation points. A2 may disappear during diastole and a P2 prolapse may be seen behind A2. The left atrial appendage must also be visible (figs 5 and 6). The two chamber posterior view only shows the posterior leaflet, mostly P2. In each view, a refined description of the lesions in grey scale is mandatory followed by colour Doppler flow analysis of direction and diameter of the jet.

In addition, detection of commissural jets and annular calcifications (fig 9), annulus diameter measurement, and description of subvalvar apparatus abnormalities are crucial. Annular dilation is assessed by annulus diameter measurement at end systole immediately before valve opening ${ }^{38}$ and by the ratio of annulus diameter to anterior mitral leaflet length $>1.3$ during diastole. The anteroposterior length and the transverse diameter of the anterior leaflet can be measured in the short axis view. The risk of systolic anterior motion after repair is increased when the anteroposterior length of the anterior leaflet is longer than the transverse diameter. In case of associated degenerative and rheumatic processes, subvalvar apparatus abnormalities have to be evaluated according to the same criteria. ${ }^{39}$

Associated lesions are possible on other scallops including destruction by infective endocarditis or restriction, ${ }^{40}$ since MVP may coexist with rheumatic or congenital disease such as atrial septal defect. In hypertrophic cardiomyopathy, prolapse of the posterior leaflet may be associated with systolic anterior motion. In ischaemic heart disease, MVP may be related to papillary muscle dysfunction. The routine evaluation of a patient with MVP should include careful inspection of the

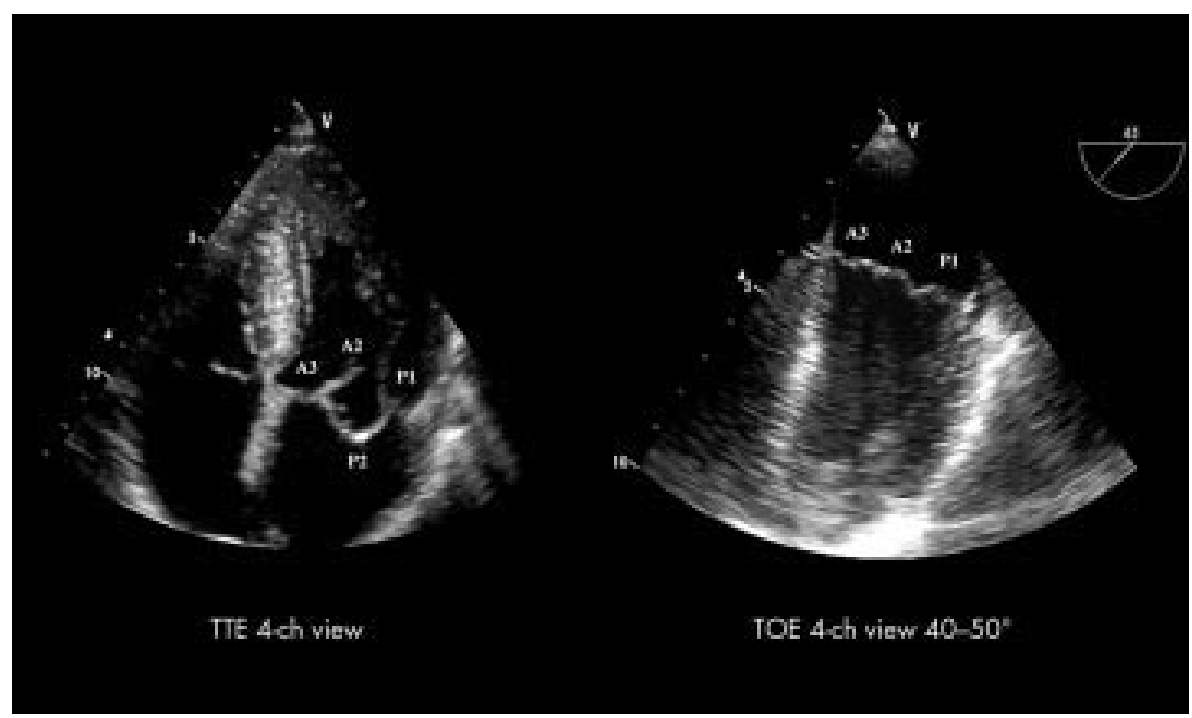

Figure 3 Left panel: transthoracic apical four chamber view in a patient with P2 prolapse. Although A3-A2-P1 scallops are usually seen in this view, the P2 scallop prolapse is seen behind A2. Right panel: transoesophageal four chamber view $40-50^{\circ}$ showing the same scallops as the transthoracic four chamber view in a normal subject. TOE transoesophageal echo; TTE, transthoracic echo. 


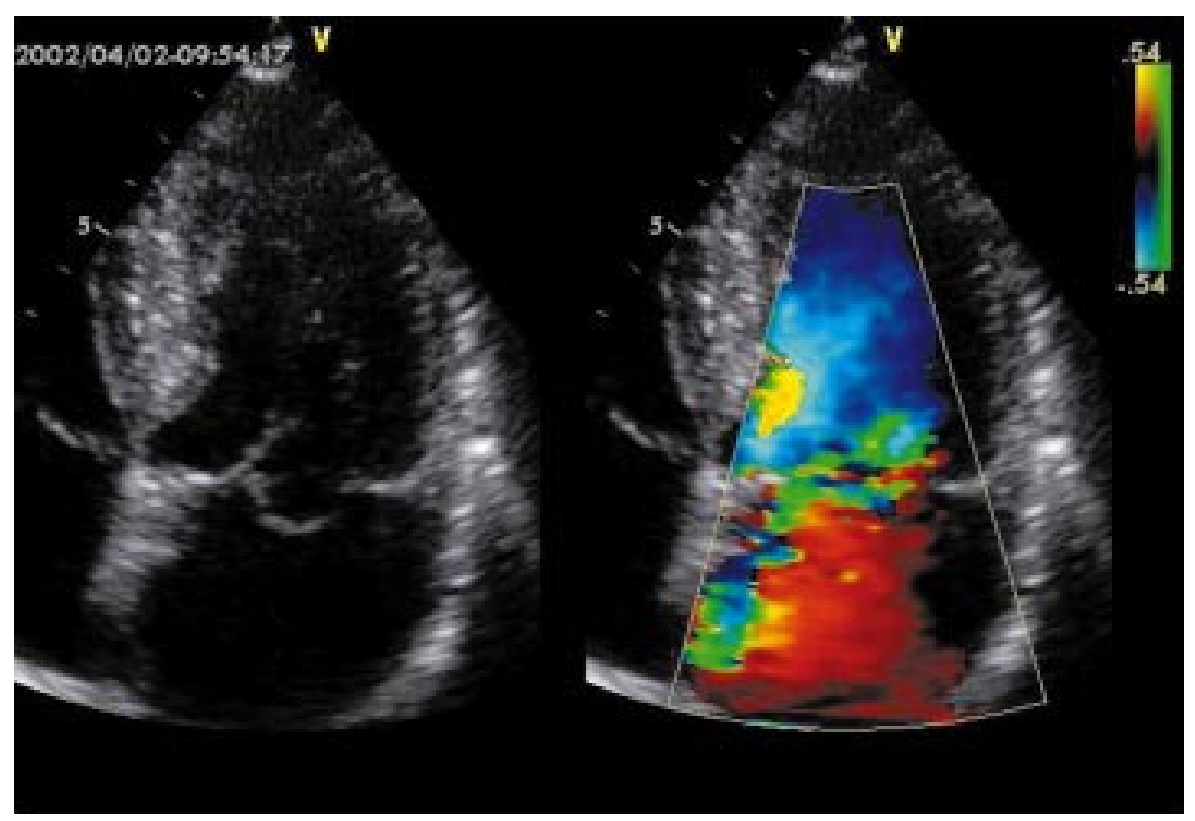

Figure 4 Transthoracic apical four chamber view in a patient with P2 prolapse. Left panel: on the grey scale image, the P2 scallop is visualised behind A2. Right panel: using colour Doppler flow in the same patient, there is an oblique jet of mitral regurgitation going behind the anterior leaflet which hugs the interatrial septum.

other valves, particularly if connective tissue disorders such as the Marfan or Ehler-Danlos syndromes are present.

Underlying valve structure, the mechanism of regurgitation, and location of pathology can be assessed by a systematic analysis of each scallop and are major determinants of the probability of successful repair. A close cooperation between the echocardiographer, the surgeon, and the pathologist including correlations between refined echo analyses, meticulous intraoperative examination of the mitral valve, and histology of surgically resected abnormal valve tissue are mandatory to achieve the best possible patient management.

The other potential complications of MVP are infective endocarditis, heart failure, and sudden death. Among adults with native valve endocarditis, MVP has been the most recognised lesion. ${ }^{41}$ The incidence of infective endocarditis rises in the presence of a murmur, whereas patients with only a click are at very low risk. ${ }^{42}$ The risk of sudden death increases slightly in patients with severe mitral regurgitation. ${ }^{30444}$ Using strict two dimensional echo criteria for the diagnosis of MVP, Gilon and colleagues showed that MVP is no more common among young patients with unexplained cerebral embolic events than among control subjects. ${ }^{45}$ The rates of heart failure, atrial fibrillation, cerebrovascular disease, and syncope were no higher among subjects with MVP than among those without prolapse. ${ }^{23}$ Thus, MVP should not be considered a cardiac cause of embolism.

\section{MANAGEMENT}

In light of the new data that have emerged during recent years, management of MVP should be based on the echocardiographic categorisation of patients according to rigorous criteria that should be adopted by all laboratories. For patients with normal variant prolapse and no murmur, prophylaxis against infective endocarditis is optional and probably unnecessary. ${ }^{25}$ Patients with primary MVP require instruction for prophylaxis, particularly those with a systolic murmur. Meticulous follow up is warranted for patients with the primary form of MVP, especially if substantial mitral regurgitation is present. Longstanding volume overload of the left ventricle can lead to left ventricular myocardial dysfunction, even in asymptomatic patients with a normal ejection fraction.

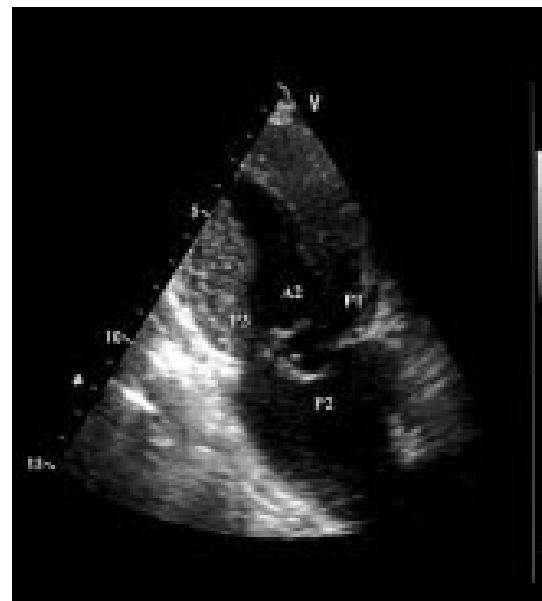

TTE 2-ch view

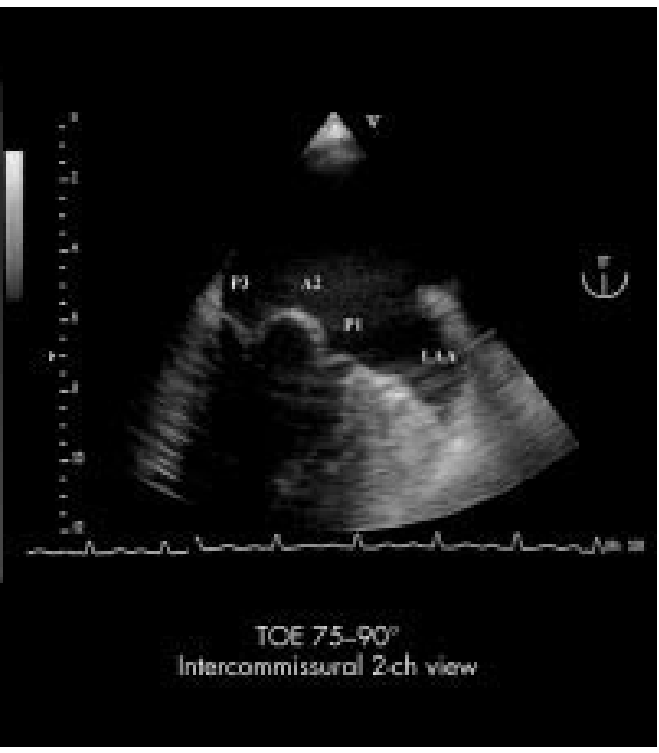

Figure 5 Left panel: transthoracic apical two chamber view in a patient with P2 prolapse. P2 scallop is visualised behind A2. Right panel: transoesophageal intercommissural wo chamber view $75-90^{\circ}$ showing the same scallops as the transthoracic view in another patient with $\mathrm{A} 2$ prolapse. LAA, left atrial appendage. 


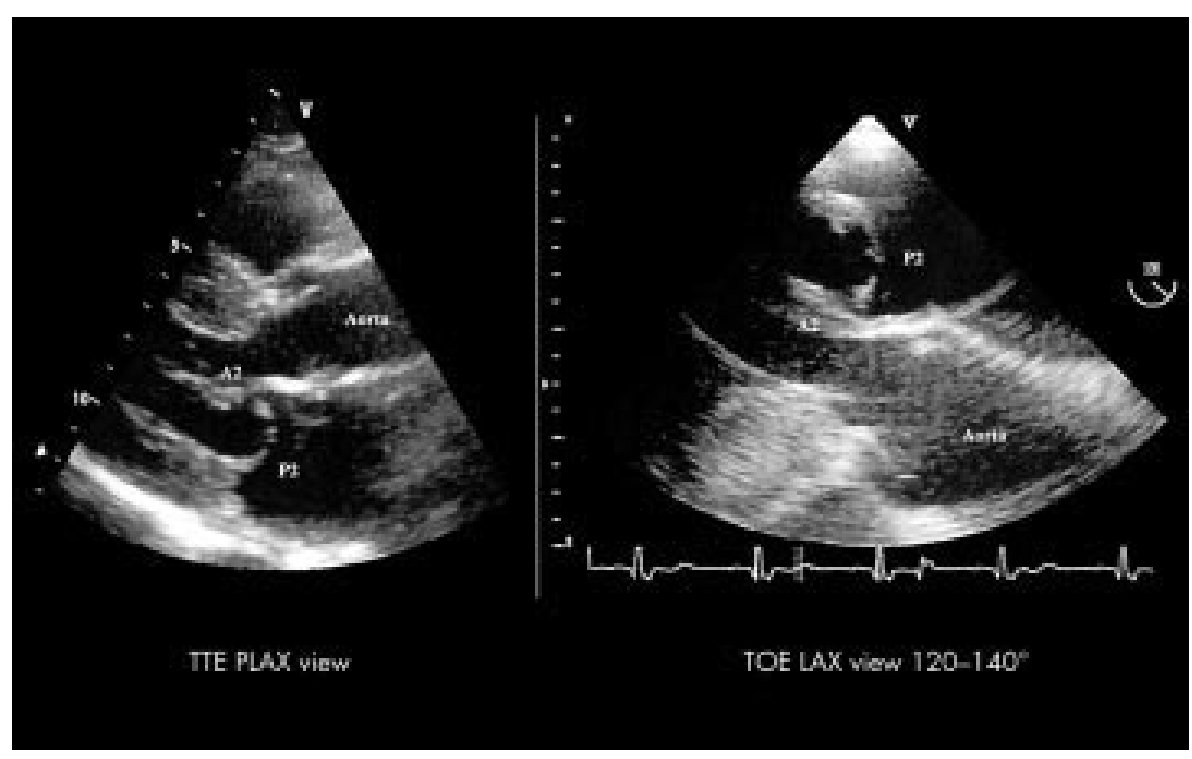

Figure 6 Left panel: transthoracic parasternal long axis (PLAX) view in a patient with P2 prolapse. In that view, the aortic valve and the ascending aorta must be well defined. Right panel: transoesophageal long axis (LAX) view $120-140^{\circ}$ in the same patient.
Valve repair is increasingly performed in patients with severe mitral regurgitation and offers the advantages of less perioperative morbidity and mortality (approximately 2\% operative mortality), preservation of the mitral subvalvar apparatus with better maintenance of LV function, freedom from anticoagulation and favourable long term outcome. ${ }^{46-48}$ Valve repair for mitral regurgitation requires understanding of the mechanism of dysfunction.

Repair procedures are based on quadrangular resection of the posterior leaflet, ring fixation of the mitral annulus, chordae transfer, sliding leaflet technique, and commissuroplasty. These techniques are often combined. The number of the Duran annular ring corresponds to the distance between the two commissures. There is a difference of three sizes between the Duran and the Carpentier rings - for example, a Duran ring 25 corresponds to a Carpentier ring 28. Chordae shortening, chordae replacement with artificial chordae implantation, and anterior leaflet plication may also be used. ${ }^{47}$

Successful repair varied from $94 \%$ in patients with prolapse or flail of posterior leaflet to $38 \%$ in patients with two or more mechanisms of regurgitation ${ }^{40}$ to $20 \%$ in patients with rheumatic disease and restricted bileaflet motion. The greater number of factors that should be considered in the decision to recommend mitral valve surgery will obviously vary with each

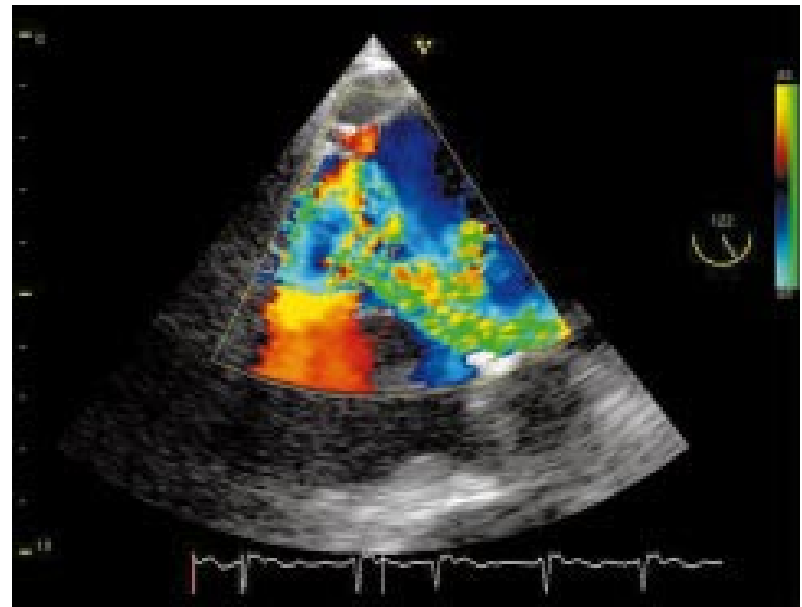

Figure 7 Transoesophageal long axis view $120-140^{\circ}$ in the same patient as in fig 6 with colour Doppler flow showing an oblique jet of mitral regurgitation behind the anterior leaflet. patient and in each hospital. Prolapse of the posterior leaflet is easy to repair. Prolapse of the anterior leaflet is more difficult to repair because it is hardly possible to perform a resection of the anterior leaflet. Mitral regurgitation of ischaemic and rheumatic associated origins are the most difficult to repair.

The operative risk for patients with severe mitral regurgitation who are asymptomatic should be reviewed for each institution. In some centres the operative risk today is very low, $0.5 \%$ for all ages ${ }^{49}$ and $0 \%$ for patients $<75$ years old. In patients $>75$ years old, the operative risk was only $3.6 \%$ for the patients in class I or II but rose to $12.7 \%$ for patients with severe symptoms. Patients operated on in New York Heart Association (NYHA) functional class I or II had a long term postoperative survival equivalent to expected survival..$^{50}$ On the basis of the Mayo Clinic experience, one can consider mitral valve surgery even if the patient has only NYHA class I symptoms, particularly in the presence of a flail mitral valve leaflet. These favourable results are an incentive for early surgery before ventricular dysfunction occurs. To achieve the benefits of early reconstructive surgery without valve replacement, there should be a strong likelihood of valve repair and the surgeon should be highly skilled in mitral valve repair surgery. In contrast, some asymptomatic elderly patients, who may incur a higher operative risk, should be followed conservatively while waiting for the development of class II symptoms.

Patients with chronic non-ischaemic severe mitral regurgitation who have NYHA functional class I symptoms and who have normal LV ejection fraction $>60 \%$ and LV end systolic diameter $<45 \mathrm{~mm}$ may be followed up medically at 3-6 month intervals. If such patients develop evidence of LV dysfunction, atrial fibrillation, or pulmonary hypertension (estimated pulmonary artery pressure of $50 \mathrm{~mm} \mathrm{Hg}$ at rest or $60 \mathrm{~mm} \mathrm{Hg}$ during exercise), the patient should be considered for cardiac catheterisation and possible mitral valve surgery, particularly if it is thought that the mitral valve can be repaired..$^{51}$

Patients who have chronic non-ischaemic severe mitral regurgitation who have class II, III, or IV symptoms should be considered for mitral valve surgery whether or not the LV function is normal ( $\mathrm{LV}$ ejection fraction $>60 \%$, LV end systolic diameter $<45 \mathrm{~mm}) .{ }^{51}$ Whenever possible, mitral valve repair should be performed. Conversely, patients with severe symptoms and severely depressed LV function (LV ejection fraction $<30 \%$ ) are generally best treated medically.

TOE assessment in the operating theatre performed before surgery is necessary to confirm the mitral valve lesions and 


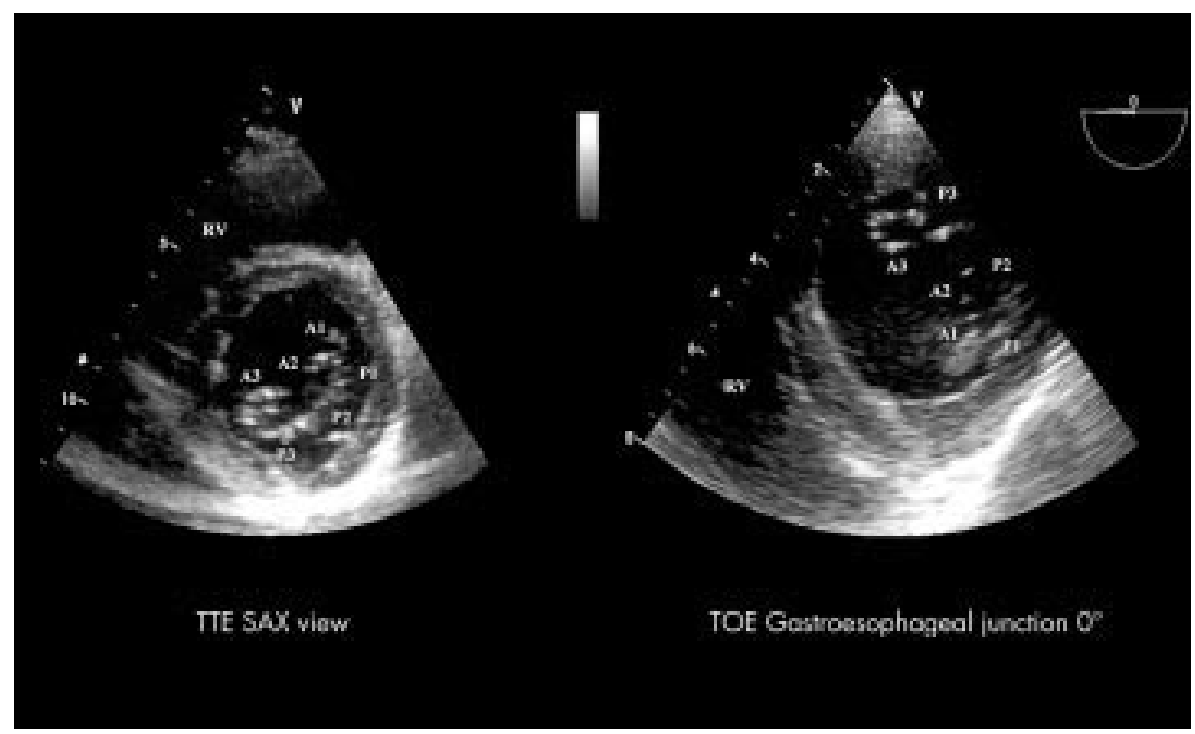

Figure 8 Left panel: transthoracic parasternal short axis (SAX) view at the level of the mitral valve showing the six scallops of the Carpentier nomenclature in a normal subject. Right panel: transoesophageal transgastric view $0^{\circ}$ showing the mitral valve scallops in a normal subject.

detect additional abnormalities that may have occurred since last evaluation. TOE assessment performed immediately after MV repair is necessary to evaluate immediate results of the repair when off pump with appropriate loading condition and systolic blood pressure $\geqslant 110 \mathrm{~mm} \mathrm{Hg}$. The TOE assessment of the reconstructed valve will guide the surgeon to decide the need to restart the patient on pump and perform further repair. That assessment includes a grey scale morphologic analysis of the leaflets, and colour Doppler flow and continuous Doppler flow analysis. The aim is to detect residual mitral regurgitation, mitral stenosis, and LV outflow tract obstruction with complete or incomplete systolic anterior motion. Separation of LV outflow tract obstruction flow from residual mitral regurgitation flow is made in deep transgastric view $0^{\circ}$ or in

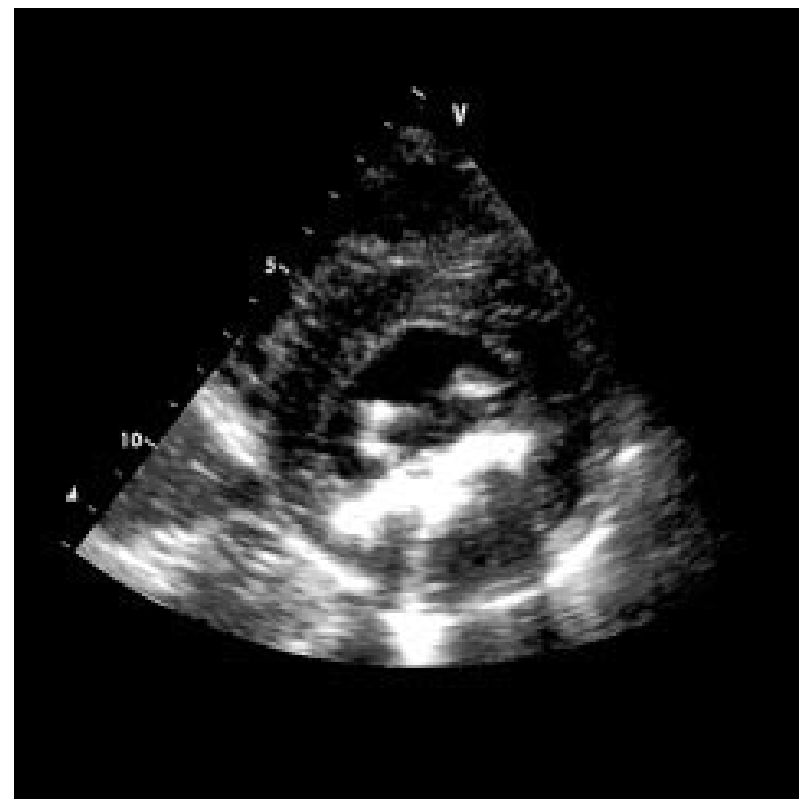

Figure 9 Transthoracic parasternal short axis view at the level of the mitral valve in a 45 year old man undergoing chronic haemodialysis. Massive calcifications of the mitral annulus are seen, mainly in the posterior region. Mitral annular calcification is recognised as a bulky echodensity adjacent to the bases of the mitral leaflets. Calcifications can extend into the bases of the leaflets and restrict their motion. Acoustic shadowing of the left atrium in the presence of mitral annular calcification may impede the detection of mitral regurgitation on transthoracic echocardiography. $120^{\circ}$ transgastric view. Anterior displacement of the posterior leaflet, narrowing of the mitroaortic angle, which has already been narrowed by left atrium enlargement, enhanced mobility, and excessive leaflet tissue may partially block LV outflow tract during systole. ${ }^{52}$ Thus, anatomic risk factors for LV outflow tract obstruction are excess leaflet tissue, non-dilated LV cavity, and narrow mitroaortic angle. A 14\% incidence of LV outflow tract obstruction was reported after prosthetic ring mitral valve repair in this high risk group of patients. The sliding leaflet technique, which reduces the height of the posterior leaflet, eliminates significant LV outflow tract obstruction in the high risk patients with no reoperations for mitral regurgitation..$^{53}$

\section{CONCLUSION}

MVP encompasses a group of degenerative disorders, which vary in severity and clinical outcome. This has led to confusion and concern for both physicians and patients concerning diagnosis and long term management. Over the past 20 years much has been learnt about the epidemiology, pathophysiology, diagnosis, and treatment of this condition. The risk of complications exists in specific patient subgroups. We now are able to recognise the normal variant form. This information has allowed a rational approach to the patient with MVP. In particular it should be emphasised that the vast majority of patients remain asymptomatic with no long term complications.

\section{Authors' affiliations}

D Pellerin, S Brecker, St George's Hospital Medical School, London, UK

C Veyrat, Institut Mutualiste Monsouris, Paris, France

Correspondence to: Dr Denis Pellerin, St George's Hospital Medical School, Blackshaw Road, London SW17 0QT, UK; dpelleri@sghms.ac.uk

\section{REFERENCES}

1 Barlow JB, Pocock WA, Marachand P, et al. The significance of late systolic murmurs. Am Heart J 1963;66:443-52.

2 Carpentier A, Deloche A, Dauptain J, et al. A new reconstructive operation for correction of mitral and tricuspid insufficiency. J Thorac Cardiovasc Surg 1971;61:1-13.

3 Carpentier A, Guerinon J, Deloche A, et al. Pathology of the mitral valve. In: Kalmanson D, ed. The mitral valve: a pluridisciplinary approach. Acton, Massachusetts: Publishing Sciences Group, Inc, 1976:65-88.

4 Carpentier A, Chauvaud S, Fabiani JN, et al. Reconstructive surgery of mitral valve incompetence: ten-year appraisal. J Thorac Cardiovasc Surg 1980;79:338-48. 
5 Barlow JB, Pocock WA, Obel IW. Mitral valve prolapse: primary, secondary, both or neither? Am Heart J 1981;102:140-3

6 Barlow JB, Pocock WA. Billowing, floppy, prolapsed or flail mitral valves? Am J Cardiol 1985;55:501-2.

7 Reid J. Mid-systolic clicks. S Afr Med J 1961;35:353-5.

8 Ronan J, Perloff J. Systolic clicks and the late systolic murmur. Intracardiac phonocardiographic evidence of their mitral origin. Am Heart J 1965;70:319-25.

9 Criley JM, Lewis KB, Humphries JO, et al. Prolapse of the mitral valve: clinical and cine-angiocardiographic findings. Br Heart $J$ 1966;28:488-96

10 Freed LA, Levine RA, Evans JC. Mitral valve prolapse (correspondence). N Engl J Med 1999;341:1471-2.

11 Devereux RB, Jones EC, Roman M, et al. Prevalence and correlates of mitral valve prolapse in a population- based sample of American Indians: the strong heart study. Am J Med 2001;111:679-85.

12 Flack JM, Kvasnicka JH, Gardin JM, et al. Anthropometric and physiologic correlates of mitral valve prolapse in a biethnic cohort of young adults: the CARDIA study. Am Heart J 1999;138:486-92.

13 Fornes P, Heudes D, Fuzellier JF, et al. Correlation between clinical and histologic patterns of degenerative mitral valve insufficiency: a histomorphometric study of 130 excised segments. Cardiovasc Pathol 1999;8:81-92.

14 Disse S, Abergel E, Berrebi A, et al. Mapping of a first locus for autosomal dominant myxomatous mitral-valve prolapse to chromosome 16p11.2-p12.1. Am J Hum Genet 1999;65:1242-51.

15 Kyndt F, Schott JJ, Trochu JN, et al. Mapping of X-linked myxomatous valvular dystrophy to chromosome Xq28. Am J Hum Genet 1998;62:627-32.

16 Cohen IS. Two-dimensional echocardiographic mitral valve prolapse: evidence for a relationship of echocardiographic morphology to clinical findings and to mitral annular size. Am Heart J 1987;1 13:859-68.

17 Rippe JM, Sloss L, Angoff G, et al. Mitral valve prolapse in adults with congenital heart disease. Am Heart J 1979;97:561-73.

18 Fontana ME, Pence HL, Leighton RF, et al. The varying clinical spectrum of the systolic click-late systolic murmur syndrome. Circulation 1970;41:807-16.

19 Meyers DG, Starke H, Pearson PH, et al. Mitral valve prolapse in anorexia nervosa. Ann Intern Med 1986;105:384-6.

20 Levine RA, Triulzi MO, Harrigan P, et al. The relationship of mitral annular shape to the diagnosis of mitral valve prolapse. Circulation 1987;75:756-67.

21 Levine RA, Stathogiannis E, Newell JB, et al. Reconsideration of echocardiographic standards for mitral valve prolapse: lack of association between leaflet displacement isolated to the apical four chamber view and independent echocardiographic evidence of abnormality. J Am Coll Cardiol 1988;11:1010-9.

22 Levine RA, Handschumacher MD, Sanfilippo AJ, et al. Three-dimensional echocardiographic reconstruction of the mitral valve, with implications for the diagnosis of mitral valve prolapse. Circulation 1989:80:589-98.

23 Freed LA, Levy D, Levine RA, et al. Prevalence and clinical outcome of mitral-valve prolapse. N Engl J Med 1999;341:1-7.

24 Nishimura RA, McGoon DC. Perspectives on mitral valve prolapse. N Engl J Med 1999;341:48-50.

25 Levy D, Savage D. Prevalence and clinical features of mitral valve prolapse. Am Heart J 1987;113:1281-90.

26 Krahn AD, Manfreda J, Tate RB, et al. The natural history of electrocardiographic preexcitation in men. The Manitoba follow-up study. Ann Intern Med 1992;116:456-60.

27 Maron BJ, Casey SA, Poliac LC, et al. Clinical course of hypertrophic cardiomyopathy in a regional United States cohort. JAMA 1999;281:650-5.

28 Duren DR, Becker AE, Dunning AJ. Long-term follow-up of idiopathic mitral valve prolapse in 300 patients: a prospective study. J Am Coll Cardiol 1988;11:42-7.

29 Devereux RB, Hawkins I, Kramer-Fox R, et al. Complications of mitral valve prolapse. Disproportionate occurrence in men and older patients. Am J Med 1986;81:751-8.

30 Nishimura RA, McGoon MD, Shub C, et al. Echocardiographically documented mitral-valve prolapse. Long-term follow-up of 237 patients. N Engl J Med 1985;313:1305-9.
31 Marks AR, Choong CY, Sanfilippo AV, et al. Identification of high-risk and low-risk subgroups of patients with mitral-valve prolapse. N Engl J Med 1989;320:1031-6.

32 Stoddard MF, Prince CR, Dillon S, et al. Exercise-induced mitral regurgitation is a predictor of morbid events in subjects with mitral valve prolapse. J Am Coll Cardiol 1995;25:693-9.

33 Cohn LH, DiSesa VJ, Couper GS, et al. Mitral valve repair for myxomatous degeneration and prolapse of the mitral valve. J Thorac Cardiovasc Surg 1989;98:987-92; discussion 992-3.

34 Carpentier AF, Lessana A, Relland JY, et al. The "physio-ring": an advanced concept in mitral valve annuloplasty. Ann Thorac Surg 1995;60: 1177-85; discussion 1 185-6.

35 Kumar N, Kumar M, Duran CM. A revised terminology for recording surgical findings of the mitral valve. J Heart Valve Dis 1995;4:70-5; discussion 76-7.

36 Veyrat C, Ameur A, Bas S, et al. Pulsed Doppler echocardiographic indices for assessing mitral regurgitation. Br Heart J 1984;51:130-8.

37 Lambert AS, Miller JP, Merrick SH, et al. Improved evaluation of the location and mechanism of mitral valve regurgitation with a systematic transesophageal echocardiography examination. Anesth Analg 1999:88:1205-12.

38 Ormiston JA, Shah PM, Tei C, et al. Size and motion of the mitral valve annulus in man. II. Abnormalities in mitral valve prolapse. Circulation 1982;65:713-9.

39 Veyrat C, Pellerin D, Sainte Beuve D, et al. Colour Doppler valvar and subvalvar flow diameter imaging versus echo score in mitral stenosis: comparison with type of surgery. Heart 1996;75:486-91.

40 Stewart WJ, Currie PJ, Salcedo EE, et al. Evaluation of mitral leaflet motion by echocardiography and jet direction by Doppler color flow mapping to determine the mechanisms of mitral regurgitation. J Am Coll Cardiol 1992;20:1353-61.

41 McKinsey DS, Ratts TE, Bisno AL. Underlying cardiac lesions in adults with infective endocarditis. The changing spectrum. Am J Med 1987:82:681-8.

42 Danchin N, Voiriot $\mathrm{P}$, Briancon $\mathrm{S}$, et al. Mitral valve prolapse as a risk factor for infective endocarditis. Lancet 1989;1:743-5.

43 Devereux RB. Recent developments in the diagnosis and management of mitral valve prolapse. Curr Opin Cardiol 1995;10:107-16.

44 Kligfield P, Levy D, Devereux RB, et al. Arrhythmias and sudden death in mitral valve prolapse. Am Heart J 1987; 1 13:1298-307.

45 Gilon D, Buonanno FS, Joffe MM, et al. Lack of evidence of an association between mitral-valve prolapse and stroke in young patients. N Engl J Med 1999;341:8-13.

46 Goldman ME, Mora F, Guarino T, et al. Mitral valvuloplasty is superior to valve replacement for preservation of left ventricular function: an intraoperative two-dimensional echocardiographic study. J Am Coll Cardiol 1987; 10:568-75

47 Deloche A, Jebara VA, Relland JY, et al. Valve repair with Carpentier techniques. The second decade. J Thorac Cardiovasc Surg 1990:99:990-1001; discussion 1001-2.

48 Enriquez-Sarano $M$, Schaff HV, Orszulak TA, et al. Valve repair improves the outcome of surgery for mitral regurgitation. A multivariate analysis. Circulation 1995;91:1022-8.

49 Sousa Uva M, Dreyfus G, Rescigno $G$, et al. Surgical treatment of asymptomatic and mildly symptomatic mitral regurgitation. J Thorac Cardiovasc Surg 1996;112:1240-8; discussion 1248-9.

50 Tribouilloy CM, Enriquez-Sarano M, Schaff HV, et al. Impact of preoperative symptoms on survival after surgical correction of organic mitral regurgitation: rationale for optimizing surgical indications. Circulation 1999:99:400-5.

51 Bonow RO, Carabello B, de Leon AC, Jr, et al. Guidelines for the management of patients with valvular heart disease: executive summary. A report of the American College of Cardiology/American Heart Association task force on practice guidelines (committee on management of patients with valvular heart disease). Circulation 1998:98:1949-84.

52 Mihaileanu S, Marino JP, Chauvaud S, et al. Left ventricular outflow obstruction after mitral valve repair (Carpentier's technique). Proposed mechanisms of disease. Circulation 1988;78:178-84.

53 Jebara VA, Mihaileanu S, Acar $C$, et al. Left ventricular outflow tract obstruction after mitral valve repair. Results of the sliding leaflet technique. Circulation 1993;88:II30-4. 


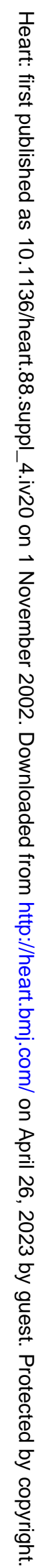

